\title{
Food Cold Chain Logistics Based on Internet of Things Technology
}

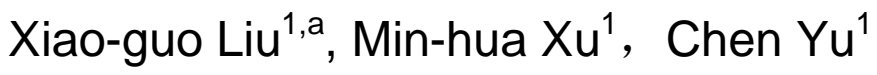 \\ ${ }^{1}$ Jilin Agricultural University, Changchun, 130118, China \\ aliuxiaoguo@jlau.edu.cn
}

Keywords: Internet of things, Food cold chain logistics, Food safety.

\begin{abstract}
Based on the food cold chain transportation, the problems of food cold chain logistics in our country is expounded. The Internet of things technology system can provide the feasible countermeasures for the food cold chain logistics.
\end{abstract}

\section{Introduction}

Storage and refrigerated transport, effectively keep food appearance, Colourand Lustre, nutrients and flavor substances, achieve quality fresh food, the purpose of to prolong food storage time. But, the food cold chain logistics in China and abroad than there are many shortage, how to quickly and efficiently enhance the level of food cold chain logistics is imminent. lot technology known as the third wave of world information industry[1], its technology widely used, how it can be applied to the field of food cold chain, has become the focus of experts and scholars.

\section{Materials and methods}

\section{A.The Internet of things technology}

Internet of things is through the radio frequency identification technology, infrared sensors, global positioning system, such as the laser scanner information sensing equipment, use of modern communication technology, the unknown objects connected to the Internet, realize the items of the intelligent identification, location, tracking and monitoring and management of a network[2]. This technique is considered to be a new revolution of science and technology, the global information industry by people from all walks of life, scholars and enterprises and the government's attention, such as the application in the field of agriculture to promote agriculturalinformatization[3], with the rapid development of modern medical applications in the field of led intelligent hospital quickly set up, etc[4], many developed countries and even be included in the informatization strategic objectives.

\section{B. The food cold chain logistics}

Cold chain for the food is based on the freezing technology, by means of refrigeration technology, the supply of raw materials, product processing, storage, transportation, distribution and retail, until the hands of consumers, its each link is always in the products required for low temperature environment, to ensure the food quality and safety, minimize loss, prevent pollution of the special supply chain system[6].

Based on the application of the Internet of things technology principle and the safety of the food cold chain logistics requirements, the Internet of things technology used in food cold chain logistics has realistic meaning that nots allow to ignore. All the food safety depends on the supply chain. Lots technology used in food cold chain logistics operation, can be real-time monitoring of food, in 
cold chain during transport and storage refrigerator complete food real-time monitoring, make the related management and customer can know the location of food information, quantity, temperature, humidity, ensure the safety of food in the process of cold chain logistics operation quality, improve food cold chain logistics operation efficiency and to carry out the meaning, put an end to food waste, improve the economic benefit[5].

\section{Results and discussion}

\section{A. Food cold chain need to improve}

Weak consciousness of cold chain logistics has become one of the biggest obstacle that baffles the development of cold chain logistics market. China is a food production and consumption power, a lot of meat, fruits and vegetables, dairy products, such as in the case of no guarantee effective cold chain distribution, and results in excessive amounts of microbes that cause various diseases, food safety problems emerge in endlessly. Residents in our country mainly cereals, vegetables, diet structure compared to meat the requirement of cold chain cold chain demand of vegetables, grain is relatively low; Diet to more heat consumption, at the request of the food safety of cold chain is relatively low; As a developing country, consumption level is limited, consumers are reluctant to accept food cold chain cost caused by price promotion, which in turn leads to a lot of fresh food dealers and consumers can not realize the importance of ensuring cold-chain logistics, know very little about the relevant food safety laws and regulations, not reasonable protection of the rights of ourselves and others, the food cold-chain propaganda is not enough, consciousness of cold chain.

\section{B. Lack of cold chain logistics management system and standards}

At present, the norms and standards of the food cold chain system in our country is not perfect, without a unified standard for enterprises to have a binding reference and execution, refinement of systemic technology standards, such as cold chain logistics operation best operating standards, cold-chain logistics can loss and efficiency standards, cold-chain food hygiene safety standards, cold storage environment temperature and refrigerated transport, such as temperature control standards, regulation is a blank. The lack of these standards caused some enterprise can according to their own operation standard operation, rely on enterprise self-discipline to maintain the quality of the product. The lack of government public sector supervision and guidance is more and more become the rapid development of food cold chain logistics a short board.

\section{Technological backwardness and weak infrastructure}

At present, there are more than 5 vehicles in China, and only a small part of it is equipped with refrigeration equipment, can reach a certain size and tonnage of professional refrigerated vehicles. In the United States, there is an average of 500 vehicles per person. And the number of cold storage cars in China is far below that level. In China, the proportion of cold storage and thermal insulation vehicles is only about $0.3 \%$, the United States is $1 \%$, Germany and other developed countries are $2 \%-3 \%$.

\section{Food cold chain traceability system construction bottleneck}

At present, China's cold chain throughout the food traceability system has not been established, the relevant departments of acquisition and processing ability of food cold chain information is still relatively weak, the lack of relevant detailed rules for the implementation of requirements and management system. To improve the traceability certification and supervision system, the recall and early warning system, to implement the management departments at all levels to complete. Moreover, the construction tracing system is a huge system engineering, capital, technology needs to be supported by the government, but also to increase the strength of support for pilot enterprises. Legislative bodies should constantly improve the relevant systems and regulations in the field of 
food safety, strengthen the supervision of the food industry, promote the establishment of food traceability information system.

\section{E. Lack of expertise}

The Internet of things technology application in the food cold chain logistics every link needs to have senior technical professionals to operate and record. At present, a lot of cold chain logistics enterprises feel "available", cultivating the specialized in the hope of cold chain logistics talents. Cold chain logistics personnel must have a certain chemical common sense, common sense of electricity and refrigeration of the structure, process, principle and other professional knowledge, this is the cold chain logistics talents must master. Cold-chain logistics talent scarcity, so far there is no specific school of cold chain logistics talent cultivation, many colleges and universities set up more is refrigeration and logistics professional, range is wide, no refining, no special cold chain logistics professional disciplines.

\section{F. Third party cold chain logistics enterprise development lag}

In China has no national professional third-party logistics company at low temperature, cold chain logistics enterprises, mostly small and medium-sized enterprises, existing weaker, smaller, no unified standards of service. Have a certain scale and resource integration, industry to promote large-scale cold chain logistics enterprise is small, and in the early stages of a fledgling, many service mode is not standard. Most of the low temperature food producers, transporters, warehouses, distributors generally smaller scale, technology and equipment backward, serious impact on the development of food cold chain technology and the improvement of quality.

\section{Food cold chain logistics countermeasures}

\section{A. Universal food safety knowledge}

In order to promote the Internet of things technology system effective application in the food cold chain logistics, fundamentally to ensure food safety, the government management department can joint media, Internet and newspaper increase food safety awareness. Consumer is the final buyer, let consumers know how to choose and buy high quality food, pay attention to food in the cold chain logistics in the whole process of transporting, put an end to shoddy food consumption, from the source raise the management level of logistics enterprises in the food cold chain logistics. Through the propaganda, popularization iot technology between consumer food safety system in the cold chain operation principle and importance, will get the guarantee of systemization cold-chain food as a food safety standards, to promote efficient utilization of the system in cold chain and operation, finally to suppress the occurrence of food safety and food waste, improve the efficiency of the national economy.

\section{B. Popularization of standardized Internet of things technology system}

Things technology among today's food-related industries in developed countries have already been promoted and applied, and achieved good results in the food processing and transportation throughout the supply chain to effectively control the quality of the food safety and hygiene. Things technology to monitor the entire food supply chain, preventive to prevent and control food contamination and damage to the whole process, better than the comprehensive quality management methods, more systematic and reasonable. China should accelerate the standardization of networking technology and its application in the food cold chain logistics, and learn from the experience of developed countries in Europe and America with its own chain logistics situation, the development of networking technology system applies and ensure their effective implementation.

\section{Strengthen infrastructure construction}


Cold chain situation, the Chinese government should encourage logistics companies to expand cold storage building, the purchase of advanced secure cold chain infrastructure and transport equipment, and improve the country's holdings of refrigerated trucks, upgrade and retire part of the life of overweight and technology behind the equipment, research and the introduction of a range of new technologies, the use of regulatory and seamless networking applications in RFID, GPS, EDI, POS and other technology in cold chain logistics, the development of modern, professional cold chain development, guarantee the quality and safety of food transportation to ensure the effective functioning of the Internet of Things technology system in the cold chain. Enterprises should vigorously promote technological innovation food cold chain logistics industry, to improve the progress of food cold chain logistics equipment logistics involved the application of advanced technology, China should strengthen research and development and technology promotion in terms of preservation technology, packaging technology, new materials technology, etc.

\section{Strengthen the construction of logistics information platform}

Information society, all walks of life control and development is inseparable from the real and effective information transfer. Application of networking technology in cold chain logistics system needs to be supported by complete information chain. States should strengthen the construction of logistics information platform, set up inventory control system, customer service and feedback system, transportation management system, comprehensive, timely, scientifically collection, processing, analysis and dissemination of all aspects of food storage and transportation information resources through the network platform and IT process monitoring, for each execution data networking technology in cold chain logistics applications generated by recording, sharing resources transportation enterprises, relevant government departments, between the market and the customer, effectively to networking technology system improve operations and develop further measures to provide true and reliable basis, and ultimately achieve the purpose of constructing a safe and effective cold chain logistics operation mechanism.

\section{E. Training professional logistics personnel}

Food cold chain logistics management personnel and a lack of engineering talent is to limit the rapid development of cold chain logistics system and effective operation of networking technology bottleneck. Cold chain logistics and physical interconnection technology system is complex and cumbersome procedures, staff training if they failed to get better, do not have the relevant quality of the actual operation and management capabilities, will lead to the Internet of Things technology system in the logistics process of vacant, can't effectively obtain information on the product. National authorities and education institutions should develop cold chain logistics personnel training policy; enterprises can actively carry out vocational training in the post and assessment; the government can set up a professional food cold chain networking technology third-party training, consulting, certification bodies, cultivate expertise and relevant experience in the professional practitioners, constantly improve their own quality, while ensuring the effective functioning of the Internet of Things technology in cold chain.

\section{F. Establishing Evaluation System}

Related enterprises in the application and the process of perfecting the system of Internet of things technology, on the attrition rate of the food you transport it, overall quality rate of rise or fall, distributors and consumers on the quality of the food there feedback record details, monthly, quarterly and annual reports of information data statistics, to verify that the Internet of things technology system in the real national conditions and the feasibility and effectiveness of logistics operation, to some extent can also be for the application of Internet of things technology in the food cold chain logistics industry development opportunities. 


\section{Summary}

China is a big country food production and consumption, the demand for food increasing year by year, food cold chain can effectively ensure food safety. The current problem of food cold chain logistics system in existence, the introduction of networking technology system, improve warehousing and distribution facilities, reduce or eliminate the process of presenting the circulation of cold chain logistics chain scission phenomenon. In the detailed implementation of the process, it can increase the loading and unloading of delivery vehicles to check the intensity of the cold chain, strict implementation of cold chain transport vehicles in transit time of check specifications, reasonable control of the delivery time. Systemic control and solve the problem of food cold chain. To achieve this goal, China should vigorously promote networking technology system, universal networking technical knowledge, training logistics professionals, strengthen the research networking technology system in the food cold chain logistics deepening and practice. Always, conduct and throughout the cold chain logistics is important for China's economy can continue, stable and healthy development. We will need to progress in service levels, and ensure the logistics professional, social skills standardization. Chinese government carried out the cold chain industry, issued a series of cold-chain infrastructure beefing, improve cold-chain logistics system, the culture of modern circulation methods and to carry out the sale of the new model, and other related fresh approach, these actions fully demonstrated the Chinese government to carry out the cold chain logistics industry's attention.

\section{Acknowledgment (include as needed)}

This research is supported by the 12th five-year plan science and technology research projects of jilin province china (20120471)

\section{References}

[1] Liu jia-hai et al. Things circulation of agricultural products based on the information. Huazhong Normal University, 2014.

[2] Zhouqin. Analysis of the current situation of Internet of things and development [J]. Ecological engineering professional technology institute of hubei province, 2011, 9(3): 41-44.

[3] Liu xiao-xing et al. Things key technologies in food quality and safety traceability applications.Science and Technology Innovation Herald, 2011(8): 22.

[4] Yujie et al. Monitoring study on the operation of the whole fresh food cold chain logistics networking technology. Logistics Technology, 2014, 33(1): 328-331.

[5] Yang shan-feng et al. Research Perspective food cold chain management strategy for food safety. Science and Technology of Food Industry, 2014(8): 36-39.

[6] Huang Cheng-zhou et al, XieRuhe. Chinese Food Cold Chain Logistics Development and Countermeasures. Logistics Engineering and Management, 2007, 29(4): 37-39. 